Proceedings of the 24th International Symposium "The Environment and the Industry" (E-SIMI 2021), 24 September 2021, online event

\title{
pH-metric method for determining the solubility and solubility products of slightly soluble hydroxides and acids
}

\author{
IGOR POVAR*, OXANA SPINU, BORIS PINTILIE
}

Institute of Chemistry, 3, Academiei str., MD 2028, Chisinau, Republic of Moldova

*Corresponding author: ipovar@yahoo.ca

$\begin{array}{lll}\text { Received: } & \text { Accepted: } & \text { Published: } \\ \text { 13.08.2021 } & 16.11 .2021 & 17.12 .2021\end{array}$

\begin{abstract}
In this paper, original methods for determining such thermodynamic characteristics as solubility product $\left(K_{S}\right)$ or the activity product $\left(K_{S}^{0}\right)$ of slightly soluble hydroxides and acids are communicated. Developed methods for determining $K_{S}$ and solubility $S$ are based only on the $p H$ values of the saturated aqueous solution for a known initial composition of the heterogeneous mixture and the equilibrium constants of an arbitrary set of possible side reactions in the aqueous natural systems. The determination of solubility $S$ and solubility product $K_{S}$ is also possible in the presence of other hydroxides or acids of known concentrations. Deduced equations allow the calculation of such characteristics, as the equilibrium concentrations of the components of slightly soluble compounds in aqueous phase and the degree of precipitation $\gamma$ of the solid phase for various initial concentrations of the components of the heterogeneous mixture which are known in the process of preparing the mixture, requiring only experimental $\mathrm{pH}$ values of a saturated solution. From the known experimental $\mathrm{pH}$ data, $S$ and $K_{S}$ were calculated for a series of hydroxides and acids of arbitrary composition. The obtained results correlated well with the known tabular values. Analysis of a number of real systems illustrated the deduced expressions, including calculations and theoretical explanations.
\end{abstract}

Keywords: slightly soluble compounds, solubility, solubility products, thermodynamic modeling

\section{INTRODUCTION}

Thermodynamic modeling is extensively used for a number of applications from research on the environmental crucial processes to regulatory necessities and policy decisions concerning authorization for industrial and agricultural wastes, quality and composition of natural waters, wastewater etc. On the other hand, in order to provide a theoretical basis for environment risk assessment and pollution remediation, the thermodynamic tabular data, namely the equilibrium constants or standard Gibbs energy for different reactions, are necessary.

In determining the solubility product $\left(K_{S}\right)$, two types of experimental data are usually used: $(a)$ the solubility is studied as a function of the initial concentrations of the compounds in solution, or $(b)$ the solubility data are supplemented by the equilibrium concentration data or the activity of one of the solution components, more commonly the $\mathrm{pH}\left(\mathrm{pH}=-\log a_{H^{+}}\right)$[1-3]. In the second case, some information on the initial concentrations becomes superfluous and therefore some of them are not usually communicated.

Currently, the study of the quantitative characteristics of heterogeneous systems, including solubility products, is mainly performed with physical-chemical methods, among which the most 
efficient is the potentiometric method. One of the strictest methods of determining $K_{S}$ is the method of measuring the activity of all ions that form the precipitate [4]. This method allows the investigation of sparingly soluble compounds in both dilute and concentrated solutions, as well as in the presence of other electrolytes. However, this method is related to some assumptions, inevitable when measuring the activities of precipitate ions. In addition, the task of creating stable and reproducible ion-selective electrodes is entirely solved only for a small number of cations and anions.

In the case of determining the activity of all the precipitate ions $a_{i}$, the obtained constant is thermodynamic (the product of activity $K_{S}^{0}$ ). For example, for the slightly soluble compound $B_{m} A_{n(S)}$ :

$$
K_{S}^{0}=a_{B^{n+}}^{m} a_{A^{m-}}^{n}
$$

If the expression for the solubility product includes the equilibrium concentrations of the solid phase components, then this constant is called the concentration constant $\left(K_{S}\right)$ :

$$
K_{S}=\left[B^{n+}\right]^{m}\left[A^{m-}\right]^{n}
$$

In this case the measured activities (for example, the $\mathrm{pH}$ of the solution, $a_{H^{+}}=10^{-p H}$ ) are recalculated in concentrations or ion concentrations are necessary to measure so as to exclude the influence of activity coefficients [5]. This correction can be avoided by using ,mixed” constants ( $K_{S}^{m i x}$ ), the expression of which usually contains the $\mathrm{H}^{+}$and $\mathrm{OH}^{-}$activities and the equilibrium concentrations of other species. Usually, the use of concentration constants is preferred, because more often it is necessary to know the concentrations of the components, and not their activities. Mixed constants are used less often, but they are very convenient for calculating chemical equilibria in chemical analysis, because the $\mathrm{pH}$ value is usually determined by the potentiometric method.

In this paper, a new method for determining the solubility product $K_{S}$, the solubility $S$ (or the residual concentration of the metal ion $C_{M}^{r}$ ) and the degree of precipitation $\gamma$ of slightly soluble hydroxides and acids is proposed. The new method is based only on the potentiometric measurement of the equilibrium $\mathrm{pH}$ value of the heterogeneous systems as a function of the initial concentrations of the precipitate components, which are known in the process of preparing the mixture. The equilibrium constant, determined in this way, is in fact a mixed constant. Based on the equations, known in the electrolyte theory, one can easily obtain the values $K_{S}^{0}$ or $K_{S}$.

\section{RESULTS AND DISSCUTION}

\section{Solubility and solubility products of slightly soluble hydroxides}

In the case of formation of a slightly soluble hydroxide of the composition $M(O H)_{n(S)}$ ), the following set of reactions that occur simultaneously is examined:

$$
\begin{array}{cc}
M(O H)_{m(S)}+m H^{+}=M^{m+}+m H_{2} O, & K_{S}=[M][H]^{-m} \\
M+i H_{2} O=M(O H)_{i}^{m-i}+i H^{+}, & K_{i}=\left[M(O H)_{i}[H]^{i} /[M]\right.
\end{array}
$$

The non-ideality of the system can be taken into account with the help of approved methods, passing from concentrations to the activities of soluble species $[5,6]$. The mass balance $(M B)$ conditions for system (1) - (2) are usually formulated in the form of equations for calculating solubility:

$$
S=[M]_{S}+[M O H]_{S} \ldots+\left[M(O H)_{i}\right]_{S}=\sum_{i=0}\left[M(O H)_{i}\right]_{S}=[M]_{S}\left(1+\sum_{i=1} K_{i}[H]^{-i}\right)=[M]_{S} \alpha_{M}
$$

Here the consequence of the law of mass action is used (2):

$$
\left[M(O H)_{i}\right]_{S}=K_{i}[M]_{S}[H]^{-i}
$$

Thus, the solubility is the total concentration of all metal ion species in solution, formed as a result of the dissolution of the solid phase particles (denoted by the subscript ,S'). The expression in parentheses in equation (3) shows the coefficient $\alpha_{M}$ of the metal ion hydrolysis side reactions. When writing the $M B$ equations (3) it is taken into account that the solid phase does not belong to 
the homogeneous system (saturated solution). The equation contains three unknown quantities $S$, $[M]$ and $[H]$, two of which need to be determined experimentally.

Here it will be revealed that the $M B$ equations are more informative and useful, which directly include the experimental quantities, measured within the residual concentration $(R C)$ method [7]:

$$
\begin{aligned}
& C_{M}^{0}=\Delta C_{M}+C_{M}^{r} \\
& C_{O H}^{0}=\Delta C_{O H}+C_{O H}^{r}
\end{aligned}
$$

where $\Delta C_{i}=n_{i} / V ; n_{i}$ shows the amount of ion " $i$ " in the precipitate in a unit volume $V, \mathrm{~mol} / \mathrm{L} ; C_{i}^{r}$ is the residual concentration of ion " $i$ " in the liquid phase, mol/L; $C_{M}^{0}$ symbolizes the total molar concentration of the metal ion in the mixture and the excess concentration of the hydroxyl ion in the mixture is noted as $C_{O H}^{0}$ [7]:

$$
\begin{aligned}
& C_{M}^{0}=\sum_{i=0}\left[M(O H)_{i}\right]=[M]\left(1+\sum_{i=1} K_{i}[H]^{-i}\right)=[M] \alpha_{M} \\
& C_{O H}^{r}=[O H]-[H]+\sum_{i=1} i\left[M(O H)_{i}\right]=K_{W}[H]^{-1}-[H]+[M]\left(\sum_{i=1} i K_{i}[H]^{-i}\right)
\end{aligned}
$$

Thus, according to the stoichiometry of the hydroxide precipitate $M(O H)_{m(S)}$,

$$
\Delta C_{O H}=m \Delta C_{M}
$$

The initial concentrations of the precipitate ions are known a priori in the process of preparing the initial solutions. Their ratio will be noted by $k=C_{O H}^{0} / C_{M}^{0}$, from where

$$
C_{O H}^{0}=k C_{M}^{0}
$$

It is obvious that the residual concentration of the metal ion (6) coincides with the solubility only in the case $k>m$ (then the index " $S$ " in equation (3) can be omitted). The substitution of relations (8) and (9) in (5) gives:

$$
k C_{M}^{0}=m \Delta C_{M}+C_{O H}^{r}
$$

Then, equation (4) is multiplied by $m$ and the obtained expression is subtracted from (10). Finally, one gets:

$$
(k-m) C_{M}^{0}=C_{O H}^{r}-m C_{M}^{r}=[O H]-[H]+[M] \sum_{i=1} i K_{i}[H]^{-i}-n[M]\left(1+\sum_{i=1} K_{i}[H]^{-i}\right)
$$

Therefore, following the operated transformations of the system of equations (4) - (5), the $M B$ equation is obtained, which contains only two unknown quantities $[M]$ and $[H]$, one of which must be measured. The latter is easily determined by the potentiometric method. Based on the obtained equation (11), a series of tasks of the direct and indirect problems of the chemical equilibrium theory can be solved, which have both theoretical and practical value. Thus, solving the equation in relation to the equilibrium concentration of the metal ion $[M]$ gives $\left(K_{0} \equiv 1\right)$ :

$$
[M]=\frac{(k-m) C_{M}^{0}-[O H]+[H]}{\sum_{i=0}(i-m) K_{i}[H]^{-i}}
$$

By calculating the $\alpha_{M}$ coefficient, the equilibrium concentration $C_{M}^{r}$ is determined, therefore the solubility $S$ of hydroxide as well, according to the equation:

$$
C_{M}^{r} \equiv S=[M] \alpha_{M}
$$

After that, it is easy to calculate the degree of precipitation of the metal ion $\gamma_{M}$ :

$$
\gamma_{M}=\frac{C_{M}^{0}-C_{M}^{r}}{C_{M}^{0}}=\frac{\Delta C_{M}}{C_{M}^{0}}=\frac{\left.\sum_{i=1} i K_{i}[H]^{-i}+\alpha_{M} \mid([O H]+[H]) / C_{M}^{0}-k\right]}{\sum_{i=0}(i-m) K_{i}[H]^{-i}}
$$

Using equation (7) to compute value $[M](12)$ and a certain $\mathrm{pH}, C_{O H}^{r}$ is also easily determined. Finally, by combining (1) and (12), the calculation equation for $K_{S}$ is obtained:

$$
K_{S}=\frac{(k-m) C_{M}^{0}-[O H]+[H]}{\sum_{i=0}(i-m) K_{i}[H]^{m-i}}
$$


Therefore, the relation (15) allows the calculation of the $K_{S}$ value only based on the experimental $\mathrm{pH}$ value, the tabular values $K_{i}$ being known. When the $K_{S}$ value is known under the predominant conditions of a unique hydroxocomplex $M(\mathrm{OH})_{i}$, then by the equation (15) its hydrolysis constant $K_{i}$ may be calculated.

Under the conditions of polynuclear hydrolysis:

$$
i M+j H_{2} \mathrm{O}=M_{i}(\mathrm{OH})_{j}+j H^{+}, K_{i j}=\left[M_{i}(\mathrm{OH})_{j}\right][H]^{j} /[M]^{i}
$$

the $M B$ equations are formulated as follows:

$$
\begin{aligned}
& C_{M}^{r}=[M]+\sum_{i=1} \sum_{j=1} i\left[M_{i}(O H)_{j}\right]=[M]+\sum_{i=1} \sum_{j=1} i K_{i j}[M]^{i}[H]^{-j} \\
& \left.C_{O H}^{r}=[H]-[O H]+\sum_{i=1} \sum_{j=0} j(O H)_{j}\right]=[O H]+[H]+\sum_{i=1} \sum_{j=1} j K_{i j}[M]^{i}[H]^{-j} .
\end{aligned}
$$

After a series of transformations, one gets:

$$
(k-m) C_{M}^{0}=[H]-[O H]+\sum_{i=1} \sum_{j=0}(j-m i) K_{i j}[M]^{i}[H]^{-j} .
$$

Consequently, even in this case, for a certain $\mathrm{pH}$ value, an equation with a single unknown $[M]$ is obtained. In the absence of cation hydrolysis, the equations (7), (13) - (15) have the form:

$$
\begin{array}{ll}
\left.C_{O H}^{r}=[H]-O H\right], & C_{M}^{r}=[M]=\left[C_{O H}^{r}+(m-k) C_{M}^{0}\right] / m \\
\gamma_{M}=\frac{k}{m}-\frac{C_{O H}^{r}}{m C_{M}^{0}}, & K_{S}=\left[C_{O H}^{r}+(m-k) C_{M}^{0}\right] /\left(m[H]^{m}\right) .
\end{array}
$$

If the initial concentrations of the precipitate components are taken in stoichiometric ratio, i.e. $k=$ $m$, then the last equations are considerably simplified:

$$
\begin{aligned}
& C_{M}^{r}=[M]=C_{O H}^{r}, \quad \gamma=1-\frac{C_{O H}^{r}}{m C_{M}^{0}}, \\
& K_{S}=\frac{C_{O H}^{r}}{m[H]^{m}}=\frac{[O H]-[H]}{m[H]^{m}} .
\end{aligned}
$$

As an illustration of the applicability of the deduced equations, the " $\mathrm{Ni}\left(\mathrm{NO}_{3}\right)_{2}-\mathrm{NaOH}-\mathrm{H}_{2} \mathrm{O}$ " system will be examined. Table 1 shows the results of the experiments, obtained in [8]. Under the studied conditions, the basic salts are not formed on the whole range of the $k=C_{\mathrm{NaOH}}^{0} / C_{\left.\mathrm{Ni}_{(\mathrm{NO}}\right)_{2}}$ values. Consider the possibility of the following reactions $\left(I=0, t=25^{\circ} \mathrm{C}\right)$ :

$$
\begin{array}{lc}
\mathrm{Ni}^{2+}+\mathrm{H}_{2} \mathrm{O}=\mathrm{NiOH}^{+}+\mathrm{H}^{+}, & \log \mathrm{K}_{10}=-9.86 \\
\mathrm{Ni}^{2+}+2 \mathrm{H}_{2} \mathrm{O}=\mathrm{Ni}(\mathrm{OH})_{2}+2 \mathrm{H}^{+}, & \log _{20}=-19.0 \\
\mathrm{Ni}^{2+}+3 \mathrm{H}_{2} \mathrm{O}=\mathrm{Ni}(\mathrm{OH})_{3}^{-}+3 H^{+}, & \log _{30}=-30.0 \\
\mathrm{Ni}^{2+}+4 \mathrm{H}_{2} \mathrm{O}=\mathrm{Ni}(\mathrm{OH})_{4}^{2-}+4 H^{+}, & \log _{40}=-44.0 \\
2 \mathrm{Ni}^{2+}+\mathrm{H}_{2} \mathrm{O}=\mathrm{Ni}_{2}(\mathrm{OH})^{3+}+H^{+}, & \log \mathrm{K}_{21}=-10.7 \\
4 \mathrm{Ni}^{2+}+4 \mathrm{H}_{2} \mathrm{O}=\mathrm{Ni}_{4}(\mathrm{OH})_{4}^{4+}+H^{+}, & \log \mathrm{K}_{44}=-27.74
\end{array}
$$

The hydrolysis constants $\left(K_{i j}\right)$ for $I=0$ were obtained from results of Baes and Mesmer [9]. The equilibrium concentration of nickel ion was calculated from equation (16), given the form:

$$
a_{4}\left[N i^{2+}\right]+a_{2}\left[N i^{2+}\right]+a_{1}\left[N i^{2+}\right]+a_{0}=0
$$

where

$$
\begin{aligned}
& a_{4}=4 K_{44}[H]^{-4}\left(1-m_{O H}^{S}\right) \\
& a_{2}=2 K_{21}[H]^{-1}\left(1-2 m_{O H}^{S}\right) \\
& a_{1}=\left(\sum_{i=0}^{4} K_{1 i}[H]^{-1}\left(i-m_{O H}^{S}\right)\right) \\
& a_{0}=K_{w}[H]^{-1}-[H]+\left(m_{O H}^{S}-k\right) C_{N i}^{0} \\
& m_{O H}^{S}=\frac{\Delta C_{O H}}{\Delta C_{N i}} .
\end{aligned}
$$


The residual concentration $C_{N i}^{r}$ was determined from the equation:

$$
C_{N i}^{r}=\left[N i^{2+}\right] \alpha_{N i},
$$

where

$$
\alpha_{N i}=1+\sum_{i=1}^{4} K_{1 i}[H]^{-i}+2 K_{21}\left[N i^{2+}\right][H]^{-1}+4 K_{44}\left[N i^{2+}\right]^{3}[H]^{-4} .
$$

The obtained equations allow drawing conclusions regarding the character and accuracy of the existing experimental data. As can be seen from Table 1, there is a good correlation between the experimental values and those calculated for a range of values $k: 0.25 \div 1.8$. At the same time, the experimental values $C_{N i}^{r}$ practically coincide with the calculated values of $\left[\mathrm{Ni}^{2+}\right]$ in the whole range of values $k$. Bulatov indicated that the nickel content was determined using dimethylglyoxime $(L)$ in the solution, obtained after mixing the initial mixture (for one hour) with the subsequent elimination of the solid phase [10]. Perhaps, the possible thermodynamic process with the participation of nickel hydroxocomplexes

$$
\frac{1}{i} N i_{i}(\mathrm{OH})_{j}^{(2 i-j)+}+2 L^{-}+\frac{j}{i} H^{+}=N i L_{2(S)}+\frac{j}{i} \mathrm{H}_{2} \mathrm{O}
$$

was established slowly, and therefore the authors of the cited paper determined basically the concentration of nickel ions after the reaction:

$$
N i^{2+}+2 L^{-}=N i L_{2(S)} \text {. }
$$

In order to assess the contribution of a certain chemical species in the $C_{N i}^{r}$ value, the molar fractions of the hydroxocomplexes were calculated:

$$
\begin{aligned}
& f_{i j}=\frac{i\left[N i_{i}(\mathrm{OH})_{j}\right]}{C_{N i}^{r}}=\frac{i K_{i j}\left[N i^{2+}\right]^{i-1}[H]^{-j}}{\alpha_{N i}} \\
& f_{10}=1-\sum_{i=1} \sum_{j=1} f_{i j} .
\end{aligned}
$$

Table 1. The results of the analysis and calculation for the system , $\mathrm{Ni}\left(\mathrm{NO}_{3}\right)_{2}-\mathrm{NaOH}-\mathrm{H}_{2} \mathrm{O}$, $t=25 \pm 0.1^{\circ} \mathrm{C}, C_{N i}^{0}=0.01 \mathrm{~mol} / \mathrm{L}$.

\begin{tabular}{c|ccc|cc}
\hline \multirow{2}{*}{$k$} & \multicolumn{3}{|c|}{ Analysis [8] } & \multicolumn{2}{c}{ Results of calculation } \\
\cline { 2 - 6 } & $C_{N i}^{r} \cdot 10^{3}, \mathrm{~mol} / \mathrm{L}$ & $\mathrm{pH}$ & $m_{O H}^{S}$ & $C_{N i}^{r} \cdot 10^{3}, \mathrm{~mol} / \mathrm{L}$ & {$\left[N i^{2+}\right] \cdot 10^{3}, \mathrm{~mol} / \mathrm{L}$} \\
\hline 0.25 & 8.65 & 6.85 & 1.85 & 8.65 & 8.644 \\
0.5 & 7.44 & 6.95 & 1.96 & 7.45 & 7.444 \\
0.75 & 6.2 & 7.0 & 1.97 & 6.20 & 6.189 \\
1.0 & 93 & 7.1 & 1.97 & 93 & 920 \\
1.25 & 3.63 & 7.2 & 1.97 & 3.66 & 3.651 \\
1.5 & 2.36 & 7.3 & 1.97 & 2.39 & 2.383 \\
1.6 & 1.86 & 7.45 & 1.97 & 1.88 & 1.875 \\
1.7 & 1.35 & 7.6 & 1.97 & 1.37 & 1.367 \\
1.8 & 0.87 & 8.0 & 1.98 & 0.91 & $9.034 \cdot 10^{-1}$ \\
1.9 & 0.37 & 9.5 & 1.98 & 0.87 & $3.531 \cdot 10^{-1}$ \\
2.0 & - & 10.25 & 2.00 & $1.942^{*}$ & $209 \cdot 10^{-2 *}$ \\
2.1 & - & 10.7 & 2.00 & $1.633^{*}$ & $238 \cdot 10^{-3 *}$ \\
2.25 & - & 11.1 & 2.00 & $2.238^{*}$ & $6.214 \cdot 10^{-4 *}$ \\
2.5 & - & 11.4 & 2.00 & $3.453^{*}$ & $1.553 \cdot 10^{-4 *}$ \\
3.0 & - & 11.6 & 2.00 & $7.467^{*}$ & $9.422 \cdot 10^{-5 *}$ \\
\hline
\end{tabular}

The evidence of $\mathrm{Ni}^{2+}$ hydroxocomplexes was performed within the range of values of $k: 2.0 \div 3.0$. As can be seen from Table 2, the complex $\mathrm{Ni}_{4}(\mathrm{OH})_{4}^{4+}$ is formed in significant quantities only for $k=$ $2.0\left(11.8 \%\right.$ of $\left.C_{N i}^{r}\right)$. The molar fraction of the species $\mathrm{Ni}_{2}(\mathrm{OH})^{3+}$ is practically zero for all $k$ values. The value of $K_{S}^{\text {mix }}$ for the reaction 


$$
\mathrm{Ni}(\mathrm{OH})_{2(\mathrm{~S})}+2 \mathrm{H}^{+}=\mathrm{Ni}^{2+}+2 \mathrm{H}_{2} \mathrm{O}
$$

was determined by the equation

$$
K_{S}^{m i x}=\left[N i^{2+}\right] a_{H^{+}}^{-2}
$$

for the range of $k: 2.0 \div 3.0$. The average obtained value $\log K_{S}^{m i x}=16.06 \pm 0.08$ from only the $\mathrm{pH}$ equilibrum data practically coincided with the value $\log K_{S}^{0}=16.11$, calculated by Baes $C$. $F$ and Mesmer R. E. [9] from the solubility data, which was measured over two hours after nickel hydroxide deposition.

Table 2. Results of the calculation of the solubility product of nickel hydroxide for the system

\begin{tabular}{|c|c|c|c|c|c|c|c|c|c|}
\hline \multirow[t]{2}{*}{$k^{*}$} & \multirow[t]{2}{*}{$p H$} & \multirow{2}{*}{$\begin{array}{c}\mathrm{I}, \\
\mathrm{mol} / \mathrm{L}\end{array}$} & \multicolumn{6}{|c|}{$f_{N_{i}(\mathrm{OH})_{j}}:(i, j)$} & \multirow[t]{2}{*}{$\log K_{S}^{m i x^{* *}}$} \\
\hline & & & $(1,0)$ & $(1,1)$ & $(1,2)$ & $(1,3)$ & $(1,4)$ & $(4,4)$ & \\
\hline 2.0 & 10.25 & 0.05 & 0.022 & 0.053 & 0.685 & 0.122 & 0 & 0.118 & 16.12 \\
\hline 2.1 & 10.7 & 0.051 & 0.002 & 0.018 & 0.652 & 0.327 & 0 & 0.001 & 16.03 \\
\hline 2.25 & 11.1 & 0.053 & 0 & 0.005 & 0.440 & 0.554 & 0.001 & 0 & 15.99 \\
\hline 2.5 & 11.4 & 0.055 & 0 & 0.001 & 0.284 & 0.713 & 0.002 & 0 & 15.99 \\
\hline 3.0 & 11.6 & 0.06 & 0 & 0.001 & 0.200 & 0.796 & 0.003 & 0 & 16.14 \\
\hline
\end{tabular}
$, \mathrm{Ni}\left(\mathrm{NO}_{3}\right)_{2}-\mathrm{NaOH}-\mathrm{H}_{2} \mathrm{O} ”, t=25 \pm 0.1{ }^{\circ} \mathrm{C}, \mathrm{C}_{\mathrm{Ni}}^{0}=0.01 \mathrm{~mol} / \mathrm{L}$.

The average value $\log K_{S}^{0}=16.06 \pm 0.08$ $S_{x} / \bar{x}=0.5 \%$

*Experimental data [8];

$* *$ For the reaction $\mathrm{Ni}(\mathrm{OH})_{2(S)}=\mathrm{Ni}^{2+}+2 \mathrm{OH}^{-}, \quad \log K_{S}^{(0)}=-11.94 \pm 0.08$.

Solubility and solubility products of slightly soluble acids

In the saturated solution of the sparingly soluble acid $H_{n} A_{(S)}$ (where $A^{n-}$ is the acid anion) it is possible to derive the following concomitant equilibria:

$$
\begin{aligned}
& H_{n} A_{(S)}=n H^{+}+A^{n-}, \quad K_{S}=[H]^{n}[A] \\
& A^{n-}+j H^{+}=H_{j} A^{j-n}, \quad K_{j}=\frac{\left[H_{j} A\right]}{[A][H]^{j}} \\
& H_{2} O=H^{+}+O H^{-}, \quad K_{w}=[H][O H]
\end{aligned}
$$

Next to the equations of the reactions the respective equilibrium constants are written. It will be admitted that the composition of all species participating in equilibria (17) - (19) is known. Taking into account the formation of the solid phase of stoichiometric composition $H_{n} A_{(S)}$, for the heterogeneous system "solid phase - saturated solution", the conditions of the mass balance can be formulated as follows:

$$
\begin{aligned}
& C_{A}^{0}=P+C_{A}, \\
& C_{A}=\sum_{j=0}\left[H_{j} A\right]=[A]\left(1+\sum_{j=1} K_{j}[H]^{j}\right)=[A] \alpha, \\
& C_{H}^{0}=n P+C_{H}
\end{aligned}
$$

where by $P$ is noted the amount of acid precipitated in one liter of solution (mol/L). According to the stoichiometry of the precipitate in the same volume $P$ moles of anion and $n P$ moles of hydrogen ions precipitate. The quantity $\alpha$ in equation (21) is the coefficient of protonation reactions (18). The initial concentration of ion $i$ in the heterogeneous mixture and its residual concentration in solution are denoted by $C_{i}$ and $C_{i}^{r}$, respectively. In practice, titrated solutions of strong acid $(\mathrm{HCl})$ or alkaline base $(\mathrm{NaOH})$ are added to study the $S(\mathrm{pH})$ dependence in investigated mixtures. Then the equation of the proton condition [6] in the system can be written as follows:

$$
C_{H}^{0}+C_{\mathrm{NaOH}}^{0}=n C_{A}^{0}+C_{\mathrm{HCl}}^{0}
$$




$$
C_{H}^{0}+[O H]=[H]+\sum_{j=1} j\left[H_{j} A\right]
$$

Solving the system of equations (22) - (24) gives:

$$
C_{H}^{0}=n C_{A}^{0}+C_{H C l}^{0}-C_{\mathrm{NaOH}}^{0}=n P+[H]-[O H]+\sum_{j=1} j\left[H_{j} A\right]
$$

Then, multiplying equation (20) by $n$ and subtracting it from (25), gives:

$$
C_{H}^{0}-n C_{A}^{0}=C_{H C l}^{0}-C_{N a o H}^{0}=[H]-[O H]+\sum_{j=1} j\left[H_{j} A\right]-n \sum_{j=0} j\left[H_{j} A\right]
$$

From the expression of the protonation constant $K_{j}$ follows:

$$
\left[H_{j} A\right]=K_{j}[A][H]^{j}
$$

With the help of the last relationship, the following transformations will be performed $\left(j=0, K_{0}=1\right)$ :

$$
\begin{aligned}
& \sum_{j=1} j\left[H_{j} A\right]=[A] \sum_{j=1} j\left[K_{j}[H]^{j}=[A] \vartheta,\right. \\
& \sum_{j=0}\left[H_{j} A\right]=[A] \sum_{j=0} K_{j}[H]^{j}=[A] \alpha \\
& \vartheta-n \alpha=\sum_{j=0}(j-n) K_{j}[H]^{j}
\end{aligned}
$$

Substituting the expressions (27) - (28) and solving in relation to $[A]$, it is obtained

$$
[A]=\frac{C_{H}^{0}-n C_{A}^{0}-[H]+[O H]}{\vartheta-n \alpha} .
$$

Hence,

$$
K_{S}=[H]^{n} \frac{C_{H}^{0}-n C_{A}^{0}-[H]+[O H]}{\vartheta-n \alpha}
$$

and

$$
S=[A] \alpha=\frac{\alpha}{\vartheta-n \alpha}\left(C_{H}^{0}-n C_{A}^{0}-[H]+[O H]\right) .
$$

When researching the solubility of acid in water $\left(C_{H}^{0}=n C_{A}^{0}\right)$, usually $[\mathrm{OH}] \cong 0$. Then equations (29) and (31) are simplified:

$$
[A]=\frac{[H]}{\vartheta-n \alpha}, \quad K_{S}=\frac{[H]^{n+1}}{n \alpha-\vartheta}, \quad S=[H] \frac{\alpha}{n \alpha-\vartheta} .
$$

Thus, the solubility and the solubility product can be calculated from the $\mathrm{pH}$ value of the saturated solution, measured using a $\mathrm{pH}$ meter. Based on known experimental $\mathrm{pH}$ values for a range of sparingly soluble acids (Table 3), their solubilities and solubility products were calculated. Table 4 shows the protonation constants of the acid anions and the known $K_{S}$ (or $K_{S}^{0}$ ) values. The solubility of acids in water, determined in other works, is presented in Table 5. As can be seen, the calculated values $S$ and $K_{S}$ correlate satisfactorily with the tabular data obtained previously.

Table 3. Experimental data on solution $\mathrm{pH}$ and calculated values of $S$ and $p K_{S}=-\log K_{S}[11,12]$

\begin{tabular}{l|lllll}
\hline Acid & $\mathbf{p H}$ & $\mathbf{t},{ }^{\circ} \mathbf{C}$ & $\mathbf{I}$ & $\mathbf{S}, \mathbf{~ m o l} / \mathbf{L}$ & $\mathbf{p K}$ \\
\hline Benzoic $\left(B^{-}\right)$ & 2.92 & 22 & $1.30 \cdot 10^{-2}$ & $2.41 \cdot 10^{-2}$ & 5.82 \\
& 2.90 & 22 & $1.40 \cdot 10^{-2}$ & $2.64 \cdot 10^{-2}$ & 5.80 \\
& 2.85 & 22 & 0.1 & $3.31 \cdot 10^{-2}$ & 5.70 \\
\hline Salicylic $\left(\mathrm{Sal}^{2-}\right)$ & 2.50 & 21 & $3.30 \cdot 10^{-3}$ & $1.25 \cdot 10^{-2}$ & 18.59 \\
& 2.48 & 21 & $1.30 \cdot 10^{-2}$ & $1.35 \cdot 10^{-2}$ & 18.55 \\
& 2.44 & 21 & 0.1 & $1.59 \cdot 10^{-2}$ & 18.47 \\
& $2.46^{*}$ & 20 & 0.1 & $1.46 \cdot 10^{-2}$ & 18.51 \\
\hline EDTA $\left(B^{-}\right)\left(Y^{4-}\right)$ & 2.75 & 23 & 0.1 & $1.25 \cdot 10^{-2}$ & 25.12 \\
\hline
\end{tabular}

*Reference [13]

It should be noted that when using the proposed method, it is necessary to observe a number of precautions: 1) the initial composition of the solution must be known exactly; 2) when using salt 
bridge chains for potentiometric measurements of $\mathrm{pH}$ at values less than $3 \mathrm{o}$ the value of the diffusion potential is of essential importance.

The calculation of $S$ and $K_{S}$ for the system "Salicylic acid $\left(\mathrm{H}_{2} \mathrm{Sal}\right)$-saturated aqueous solution" will be examined in more detail. Possible equilibria in this system are indicated in the Table 4. The $\mathrm{pH}$ values of saturated aqueous solutions were determined in the absence of other acids and bases, therefore $C_{H}^{0}=n C_{A}^{0}$. Then equations (20) - (22) take the form:

$$
K_{S}=\frac{[H]^{3}}{2+K_{1}[H]}, \quad S=\frac{[H]+K_{1}[H]^{2}+K_{2}[H]^{3}}{2+K_{1}[H]} .
$$

The $K_{l}$ constant was recalculated at the respective ionic strength using the extended Debye-Hückel equation. The activity coefficient of the hydrogen ion $f_{H}$ was calculated according to the Kielland equation:

$$
\log f_{H}=-\frac{0.506 \cdot I^{1 / 2}}{1+2.97 \cdot I^{1 / 2}}
$$

The concentration of hydrogen ions was determined using the equation:

$$
[H]=10^{-p H} / f_{H} \text {. }
$$

If instead of equilibrium concentration the activity $a_{H}=10^{-p H}$ is used, then a mixed constant is obtained:

$$
K_{S}^{m i x}=a_{H}^{3} /\left(2+K_{1} a_{H}\right) .
$$

The activity product was calculated according to Vasiliev's equation:

$$
\log K_{S}^{0}=\log K_{S}-\frac{(2+1) \times 0.506 \times(1)^{2} \times(-2)^{2} \times I^{1 / 2}}{1+1.6 \times I^{1 / 2}}
$$

or using the Davies equation:

$$
\log K_{S}^{0}=\log K_{S}-(2+1) \times 0.506 \times(1)^{2} \times(-2)^{2}\left(\frac{I^{1 / 2}}{1+I^{1 / 2}}-0.3 I\right) \quad(B) .
$$

For the examined conditions the calculation according to equations $(A)$ and $(B)$ gives practically the same results.

Table 4. The values of the equilibrium constants used in the calculations

\begin{tabular}{l|cccc}
\hline \multicolumn{1}{c|}{ Reaction } & $\mathrm{t},{ }^{\circ} \mathrm{C}$ & $\mathrm{I}$ & $\operatorname{logK}\left(\right.$ or $\left.\log \mathrm{K}_{\mathrm{S}}\right)$ & Reference \\
\hline$Y^{4-}+H^{+}=H Y^{3-}$ & 20 & 0.1 & 10.26 & {$[14]$} \\
$Y^{4-}+2 H^{+}=H_{2} Y^{2-}$ & 20 & 0.1 & 16.42 & {$[14]$} \\
$Y^{4-}+3 H^{+}=H_{3} Y^{-}$ & 20 & 0.1 & 19.09 & {$[14]$} \\
$Y^{4-}+4 H^{+}=H_{4} Y$ & 20 & 0.1 & 21.09 & {$[14]$} \\
$Y^{4-}+5 H^{+}=H_{5} Y^{+}$ & 20 & 0.1 & 22.69 & {$[14]$} \\
$Y^{4-}+6 H^{+}=H_{6} Y^{2+}$ & 20 & 0.1 & 23.59 & {$[14]$} \\
$\mathrm{Sal}^{2-}+H^{+}=H S a l^{-}$ & 25 & 0 & 13.52 & {$[15]$} \\
$\mathrm{Sal}^{2-}+2 H^{+}=H_{2} S a l$ & 25 & 0 & 16.56 & {$[15]$} \\
$B^{-}+H^{+}=H B$ & 25 & 0 & 20 & {$[15]$} \\
$H_{4} Y_{(S)}=Y^{4-}+4 H^{+}$ & 20 & 0.1 & -25.13 & {$[16]$} \\
$H_{2} \mathrm{Sal}_{(S)}=\mathrm{Sal}^{2-}+2 H^{+}$ & 21 & 0 & -18.52 & {$[11]$} \\
$\mathrm{HB}_{(S)}=B^{-}+H^{+}$ & 22 & 0 & -5.89 & {$[17]$} \\
$\mathrm{HB}_{(S)}=B^{-}+H^{+}$ & 25 & 0 & -5.77 & \\
\hline
\end{tabular}

Table 5. Tabular values of the acid solubility in water

\begin{tabular}{l|cccc}
\hline \multicolumn{1}{c|}{ Acid } & $\mathrm{pH}$ & $\mathrm{t},{ }^{\circ} \mathrm{C}$ & $\mathrm{S}, \mathrm{mol} / \mathrm{L}$ & Reference \\
\hline EDTA & 2.86 & - & $0.72 \cdot 10^{-3}$ & {$[18]$} \\
EDTA & Saturated solution (s.s.) & 25 & $1.70 \cdot 10^{-3}$ & {$[19]$} \\
Salicylic & s.s. & 20 & $1.30 \cdot 10^{-2}$ & {$[20]$} \\
Salicylic & s.s. & 25 & $1.59 \cdot 10^{-2}$ & {$[20]$} \\
Benzoic & s.s. & 20 & $2.38 \cdot 10^{-3}$ & {$[20]$} \\
Benzoic & s.s. & 23.5 & $2.62 \cdot 10^{-3}$ & {$[21]$} \\
\hline
\end{tabular}




\section{CONCLUSIONS}

Novel methods for determining such thermodynamic characteristics as solubility product ( $\left.K_{S}\right)$ of slightly soluble hydroxides and acids are displayed. Developed methods for determining $K_{S}$ and solubility $S$ are based only on the $\mathrm{pH}$ values of the saturated aqueous solution for a known initial composition of the heterogeneous mixture and the equilibrium constants of an arbitrary set of possible side reactions in the aqueous natural systems. The determination of solubility $S$ and solubility product $K_{S}$ is possible when other hydroxides or acids of known concentrations are present. Derived equations permit the calculation of a series of characteristics, as the equilibrium concentrations of the components of slightly soluble compounds in aqueous phase and the degree of precipitation $\gamma$ of the solid phase for different initial concentrations of the components of the heterogeneous mixture, known in the process of preparing the mixture, requiring only experimental $\mathrm{pH}$ values of saturated solution. From the known experimental $\mathrm{pH}$ data, $S$ and $K_{S}$ were calculated for a number of hydroxides and acids of arbitrary composition. The obtained results correlated well with the accepted tabular values. Analysis of a number of real systems exemplifies the validity of derived equations.

\section{ACKNOWLEDGEMENTS}

This work is a part of the Moldovan State Program (2020-2023) "Study and management of pollution sources to develop recommendations for implementing measures to mitigate the negative impact on environment and human health", Project number: 20.80009.7007.20.

\section{REFERENCES}

[1] POVAR, I., Russ. J. Inorg. Chem., 41, no. 7, 1996, p. 1167-1172. [English translation]

[2] POVAR, I., SPINU, O., Book of Abstracts of the 3rd International Conference on Analytical Chemistry, Iasi, Romania, August 28-31, 2016, Poster session 3 - Environmental Analysis P1-EA.

[3] KULESHOVA, O. \& KARABIN, L., Solubility products, Nauka, Moscow, 1983. [In Russian]

[4] XU, Y., DING, S. H., FENG, W. J., ZHOU, G. P., LIU, Y. G., Acta Cryst., 62, no. 7, 2006, p. 47 - 49, https://doi.org/10.1107/S1600536806022665.

[5] BECK, M. T., NAGYPAL, I., \& WILliAMS, D. R., Chemistry of complex equilibria, Horwood, Chichester, New York, 1990.

[6] BUTLER, J. N., Carbon dioxide equilibria and their applications, Routledge, Boca Raton, 2019.

[7] BERESNEV, E. N., Residual concentration method. Nauka, Moscow, 1992. [In Russian]

[8] TANANAEV, I. B., BOKMELDER, M. YA., Russ. J. Inorg. Chem., 2, no.12, 1957, p. 27002708. [In Russian]

[9] BAES, JR.C.F., MESMER, R.E., Am. J. Sci., 281, no. 7, 1981. https://doi.org/10.2475/ajs.281.7.935.

[10] ECONOMOU, I. G., Ind. Eng. Chem. Res., 41, no. 5, 2002, p. 953-962. https://doi.org/10.1021/ie0102201.

[11] BULATOV, M. I., Izv. Vyssh. Uchebn. Zaved. Khim. Khim.Tekhnol., 17, no. 4, 1974, p. 507 510. [In Russian]

[12] POVAR, I., Abstracts of the XXIII Session of Scientific Communications, Caciulata-Valcea, Romania, 8-10 October 1997, p. 47.

[13] SMYSHLYAEV, S.I., Izv. Vyssh. Uchebn. Zaved. Khim. Khim. Tekhnol., 15, no. 1, 1974, p. 6-8.

[14] SCHWARZENBACH, G., FLASCHKA, H., Complexometric Titrations, Second edition, Methuen London, 1969.

[15] GORONOVSKY, I. T., NAZARENKO, YU. L., NEKRYACH, E. F., A short guide to chemistry, Naukova Dumka, Kiev, 1987. [In Russian]

[16] TANANAEV I. V., TERESHIN G.S., Zhurn. Neorg.Khim., 8, no. 10, 1963, p. 2258-2271. [In Russian]

[17] MECHELYNCK, PH., SCHIETEKATTE, W., Analyt. Chim. Acta, 19, no. 6, 1958, p. 577579. [In Russian] 
[18] PALEY, P. N., UDALTSOVA N. I., Zhurn. Neorg.Khim., 5, 1960, p. 2315-2318. [In Russian] [19] PERELMAN, F. M., Prediction of solubility in water-salt systems, Znaniye, Moscow, 1972. [In Russian]

[20] MATUSEVICH, L. N., Crystallization from solutions in the chemical industry, Khimiya, Moscow, 1968. [In Russian]

[21] BUGAEVSKY, A. A., KHOLIN, YU. V., Programs for calculating equilibrium constants in solutions, Kharkov University Publishing House, Kharkov, 1988. [In Russian]

Citation: Povar, I., Spinu, O., Pintilie, B., pH-metric method for determining the solubility and solubility products of slightly soluble hydroxides and acids, Rom. J. Ecol. Environ. Chem., 2021, 3, no.2, pp. 32-41.

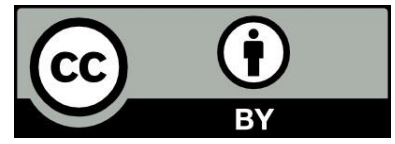

(C) 2021 by the authors. This article is an open access article distributed under the terms and conditions of the Creative Commons Attribution (CC BY) license (http://creativecommons.Org/licenses/by/4.0/). 